\title{
Robotic Assisted Sacroplasty: A Case Report
}

\author{
Robot Destekli Sakroplasti: Olgu Sunumu
}

Mehmet Resid ONEN, Mehmet SIMSEK, Sait NADERI

Umraniye Teacbing and Research Hospital, Department of Neurosurgery, Istanbul, Turkey

Corresponding Author: Mehmet Resid ONEN / E-mail: mresit@hotmail.com, mresid@gmail.com

\begin{abstract}
AIM: Sacral insufficiency fracture is an important cause of lower back and groin pain among the osteoporotic population. Diagnosis and treatment of SIFs are challenging. Currently, surgical treatment includes sacroplasty under C-arm fluoroscopy or computed tomography. Both techniques have a risk of accuracy and high radiation exposure. A sacral insufficiency fracture patient treated using robotic assisted surgery is presented and present literature is discussed.
\end{abstract}

METHOD: A bilateral sacral insufficiency fracture patient with an additional L5 osteoporotic vertebra fracture is treated by bilateral percutaneous vertebroplasty using robotic assisted surgery.

RESULTS: Robotic assisted surgery provided less $x$-ray exposure to the patient and the surgeon with additional accuracy and comfort.

CONCLUSION: Robotic assisted surgery in treatment of sacral insufficiency fracture can be an important alternative method.

KEYWORDS: Robotic assisted spine surgery, Sacral insufficiency fractures, Sacroplasty

Öz

AMAÇ: Osteoporotik popülasyonda sakral yetmezlik fraktürleri önemli bel ve kalça ağrısı sebebidir. Sakral yetmezlik fraktürlerinin tanı ve tedavisi farklılık göstermektedir. C-kollu skopi veya bilgisayarlı tomografi eşliğinde sakroplasti girişimi günümüz cerrahi yaklaşımıdır. Her iki teknikte yüksek risk ve yüksek radyasyon riski taşımaktadır. Bu çalışmada, robotik sistemle sakroplasti uygulanan bir olgu ve literatür incelemesi yapılmıştır.

YÖNTEM ve GEREÇLER: Osteoporotik L5 ve bilateral sakral yetmezlik fraktürü olan bir olguya robotik sistemle bilateral perkütan L5 ve sakral vertebroplasti uygulanmıştır.

BULGULAR: Robotik sistemle yapılan cerrahide klasik C-kollu skopi ile karşılaştırıldığında daha güvenli ve yüksek doğruluk ile birlikte daha düşük radyasyona maruz kalma oranları elde edilmiştir.

SONUÇ: Sakral yetmezlik fraktürlerinde robotik sistemle cerrahi girişim önemli bir alternatif yöntem olabilir.

ANAHTAR SÖZCÜKLER: Robot destekli spinal cerrahi, Sakral yetmezlik kırıkları, Sakroplasti

\section{INTRODUCTION}

Sacral insufficiency fractures (SIF) are an important cause of lower back and groin pain among the osteoporotic population. The diagnosis and treatment of SIFs is challenging. The conventional treatment algorithm for SIFs includes bed rest, immobilization, use of a lumbosacral orthosis and analgesic therapies $(12,14,26,27)$. Such treatment approaches may be complicated by problems in many organ systems, including deep vein thrombosis, pulmonary embolism, muscle atrophy, osteoporosis, pneumonia, decubitus ulcers, psychiatric problems and constipation $(7,10,15)$.

Sacroplasty, a surgical option for treating SIFs, increases the strength of the sacrum in order to eliminate sacral insufficiency. Injection of polymethylmethacrylate (PMMA) into the sacrum increases osteoporotic bony resistance and also relieves pain through thermal and chemical factors $(1,22,8)$. Sacroplasty was first reported in sacral metastatic lesions in 2001 (13).
Classically, the sacroplasty procedure is performed percutaneously with the guidance of C-arm fluoroscopy or computerized tomography (CT). Both C-arm fluoroscopy and CT have their own advantages and disadvantages in terms of safety, accuracy, and radiation exposure.

Spinal robotic surgery was first introduced in clinical applications in 2005 for lumbar and thoracic pedicle screw fixation procedures, and its indications were soon expanded to spinal column biopsies, vertebroplasties and kyphoplasties. Although there are some reported cases of robotic assisted kyphoplasty, there are no reports of a robotic-guided sacroplasty $(18,23)$. We present a case report of a roboticguided sacroplasty and L5 vertebroplasty performed in an osteoporotic patient with a sacral insufficiency fracture and an L5 compression fracture.

\section{Study Design}

A sacral insufficiency fracture patient treated using robotic assisted surgery is presented and present literature is discussed. 


\section{CASE REPORT}

A 72-year-old female patient who complained of 45 days of lower back and bilateral groin pain following a fall while walking was admitted to our department. The patient had difficulty walking, and the pain was aggravated by standing and sitting. A physical examination revealed severe tenderness and pain with palpation of the lumbosacral region and bilaterally on the sacral wings. Preoperative visual analogue scale (VAS) scores for both her lower back and groin pain were 8 points.

Technetium 99m methylene diphosphonate (99mTc-MDP) bone screening revealed increased activity in the $L 5$ and sacral regions (Figure 1). A lumbar CT study indicated a loss of height in L5, particularly in its middle column, as well as increased sclerosis of the inferior end-plate and a loss of bone marrow in the sacral wings (Figure $2 A, B$ ). Lumbar magnetic resonance imaging (MRI) demonstrated L5 height loss associated with increased intensity in the inversion-time inversion-recovery (STIR) sequence and heterogeneous hypointense regions of $L 5$ and the sacrum in $\mathrm{T} 1$ - and $\mathrm{T} 2$-weighted MR images (Figure 3).

Considering the findings, a diagnosis of osteoporotic L5 and sacral insufficiency were made, and treatment with robotic assisted L5 kyphoplasty and sacroplasty was planned.

Preoperative planning was performed with the robotic system's software using pre-surgical lumbosacral axial, sagittal and coronal CT images (Renaissance Surgical Guidance Robot Mazor Robotics Ltd., Caesarea, Israel) (Figure 4).

The route of access to $L 5$ and the sacral wings were determined virtually based on the $\mathrm{CT}$ scan, and locations of cement

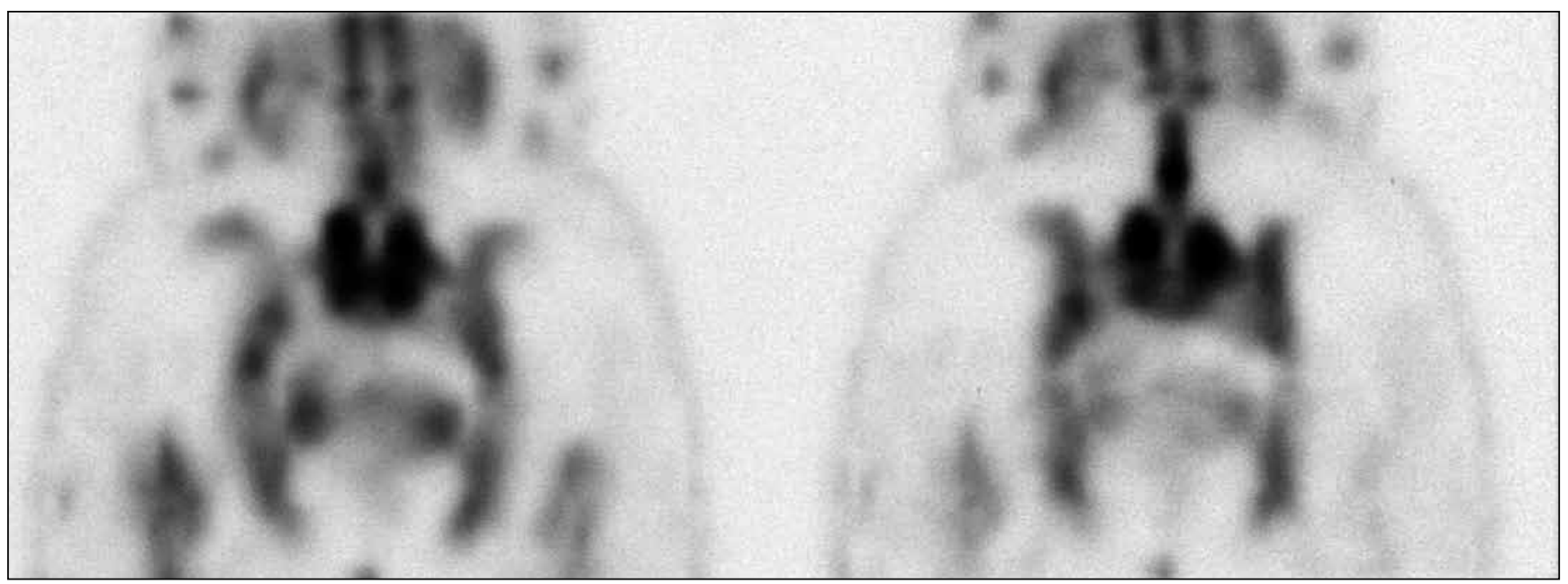

Figure 1: Bone scintigraphy (99mTc-MDP), showing increased activity in L5 vertebral body and sacral regions.

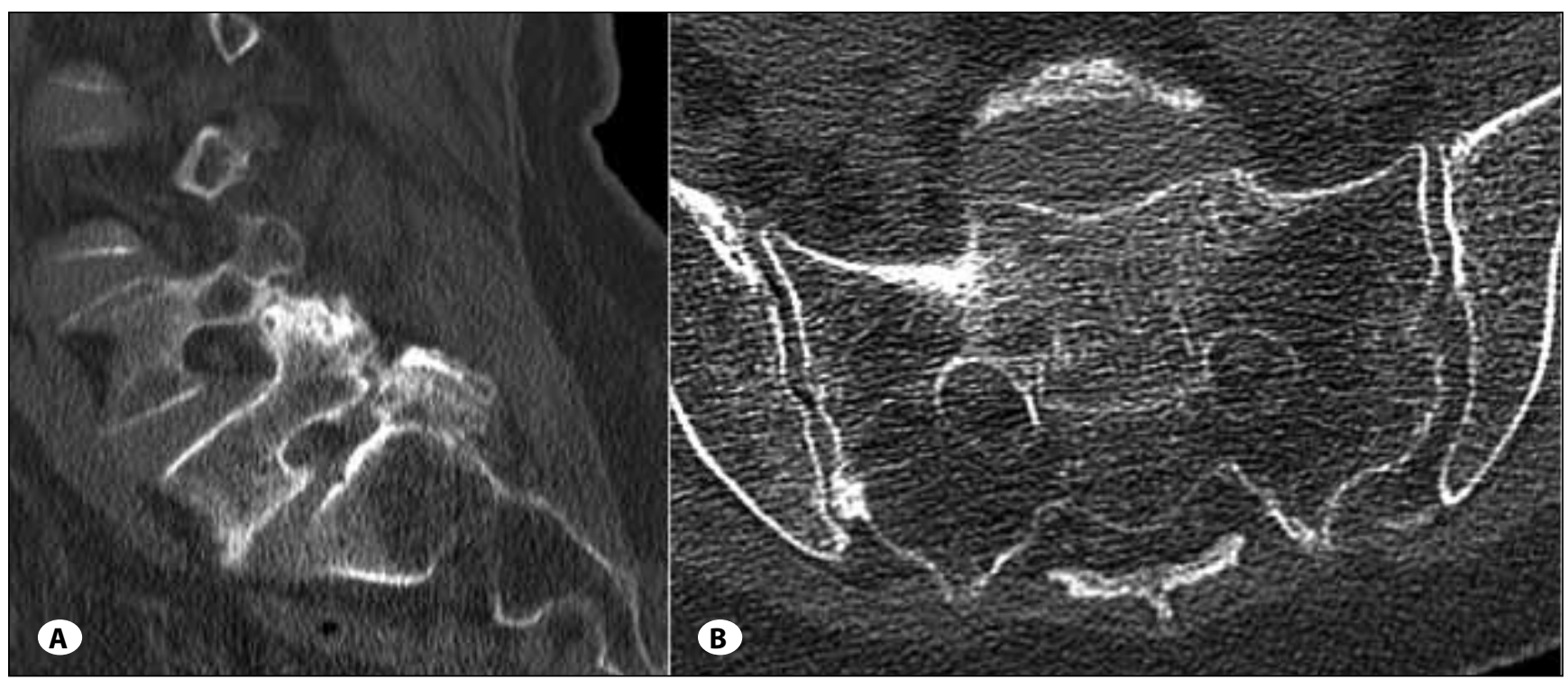

Figure 2: Appearance of lumbosacral CT A) Sagittal lumbosacral spine CT reveals L5 vertebral body height loss. B) Coronal sacral CT reveals loss of bone marrow in sacral wings. 
injection were planned. During the preoperative preparation phases in the operating room, C-arm fluoroscopy calibration of the robotic system was accomplished by synchronizing anteroposterior (AP) and 60-degree fluoroscopic images of the region of interest and a proprietary fiducial array with the CT images.

The patient was placed in a prone position under sterile conditions and general anesthesia. A bed-mounted fixation apparatus for the robotic system was fixated to the surgical table. Entry points for the L5 kyphoplasty and sacroplasty were marked based on the coordinates determined by preoperative CT analysis. Four K-wires were placed under robotic guidance into the target points. K-wires were later replaced with 11-gauge vertebroplasty cannulas (Figure 5).

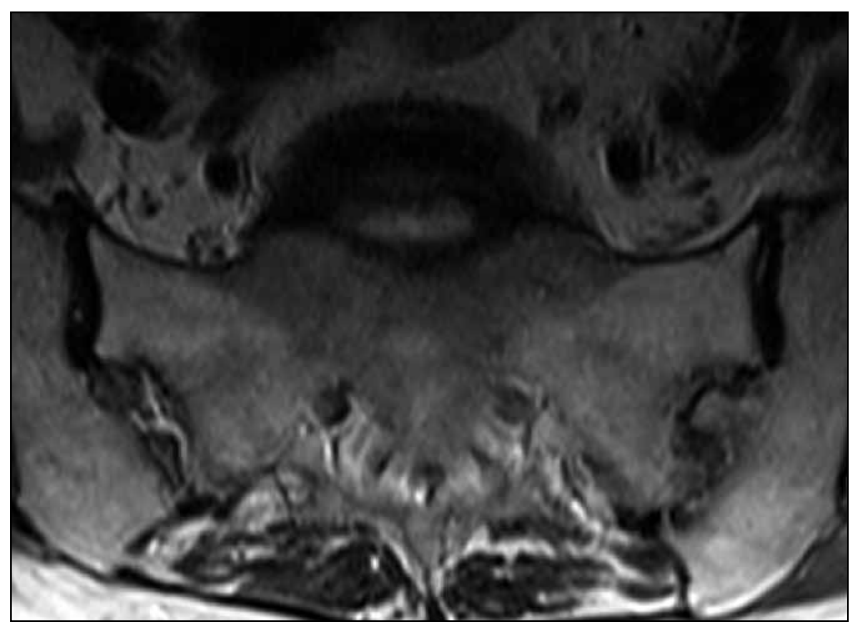

Figure 3: Axial Lumboscaral T2 weight MR shows loss of marrow in sacral wings.
After bilateral L5 kyphoplasty, a bilateral sacroplasty procedure was performed using PMMA by injecting 3 cc into each side. All stages were confirmed using lateral and AP fluoroscopy (Figure 6).

Approximately $12 \mathrm{mGy}$ of x-ray radiation was used during the lumbosacral $\mathrm{CT}$ before surgery for robotic diagnosis and planning. Preoperative $\mathrm{X}$-ray images were taken 4 times during the injection of cement.

\section{DISCUSSION}

To the best of our knowledge, this is the first report of roboticguided sacroplasty. It shows that a sacroplasty can be planned and performed effectively with less radiation exposure under robotic guidance.

There is no generally recognized consensus on an approach for sacroplasty. There are two major sacroplasty techniques: the short-axis and long-axis techniques. In the long-axis technique, a long trace is passed along the sacral wing in the caudocephal direction; in the short-axis technique, a posterior-anterior approach is used, with a trajectory similar to that of a sacral wing screw. It was reported that in the long-axis technique, PMMA can be directly injected along the fracture line, but the procedure is associated with a potential risk of PMMA leakage into the sacral foramen and perforation of the anterior cortex $(3,4,6,24,21)$. It is reported that the lateral zone of the sacrum is the safest zone for sacroplasty $(1,11)$.

Although the sacral wing and sacroiliac joint can be seen easily on AP fluoroscopy images, lateral imaging of the sacral wing is less straightforward and requires experience to avoid malposition of the sacral cannula. Therefore,

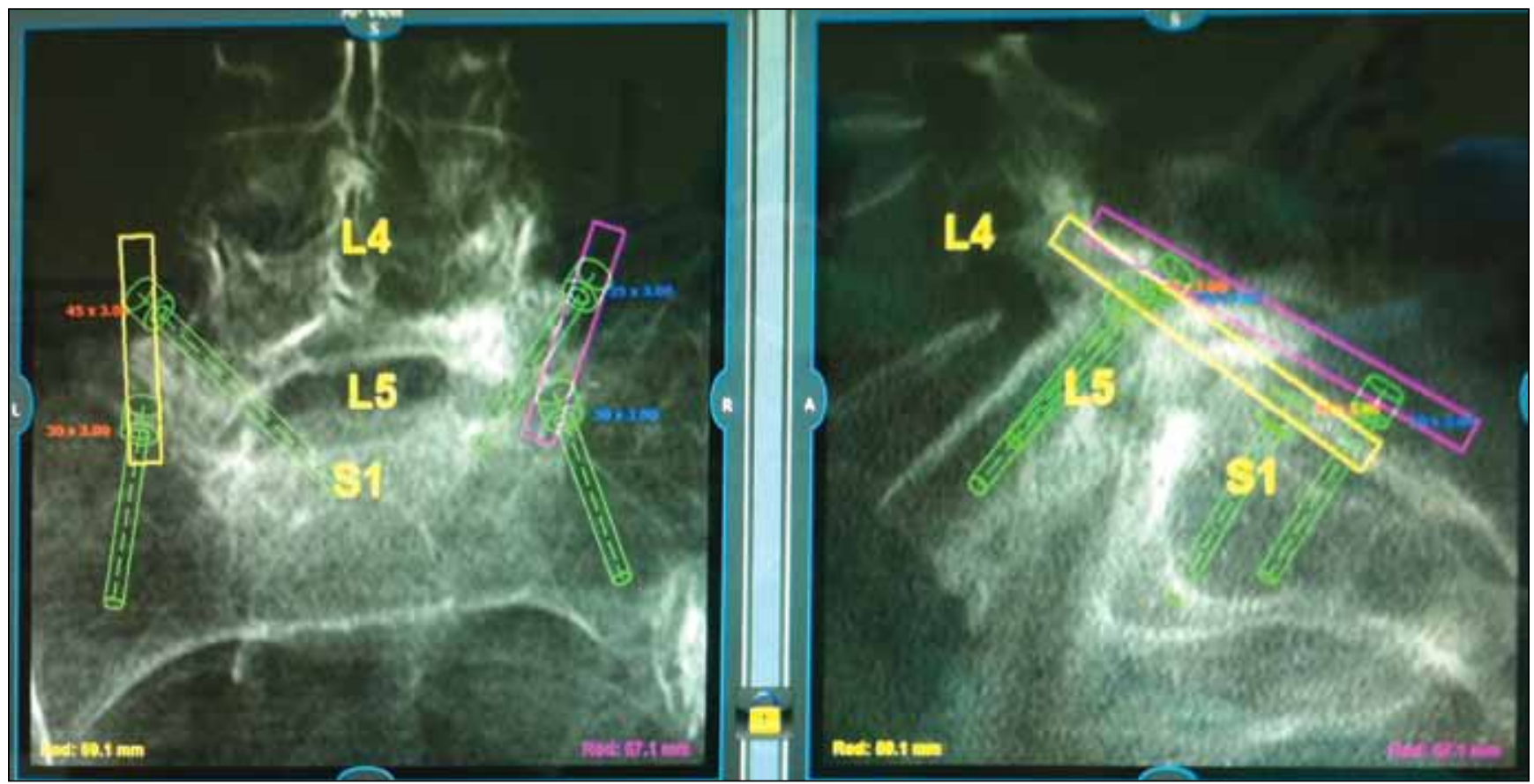

Figure 4: Preoperative planning of L5 kyphoplasty and sacroplasty with Mazor Robotic System protocol. 
some authors recommend CT-guided sacroplasty $(15,20)$ instead of sacroplasty under C-arm fluoroscopy. Although the advantages gained by CT-guided sacroplasty were emphasized by some authors $(5,11,16,17,20,25)$, real-time fluoroscopic imaging is needed for visualizing cement leakage. Moreover, the use of CT is associated with higher radiation exposure for both patients and operating room staff $(11,19)$.
The radiation exposure with a robotic system adaptable $\mathrm{CT}$ is lower than that of conventional CT. A patient with a normal $\mathrm{BMI}$ is exposed to approximately $50 \mathrm{mGy}$ of X-radiation during a standard lumbar CT. Conversely, this value is approximately $12 \mathrm{mGy}$ in CT images obtained using a robotic protocol $(9,2)$.

In vertebroplasty and kyphoplasty, the exposure time is very dependent on the surgeon (9), but it is high. A study found
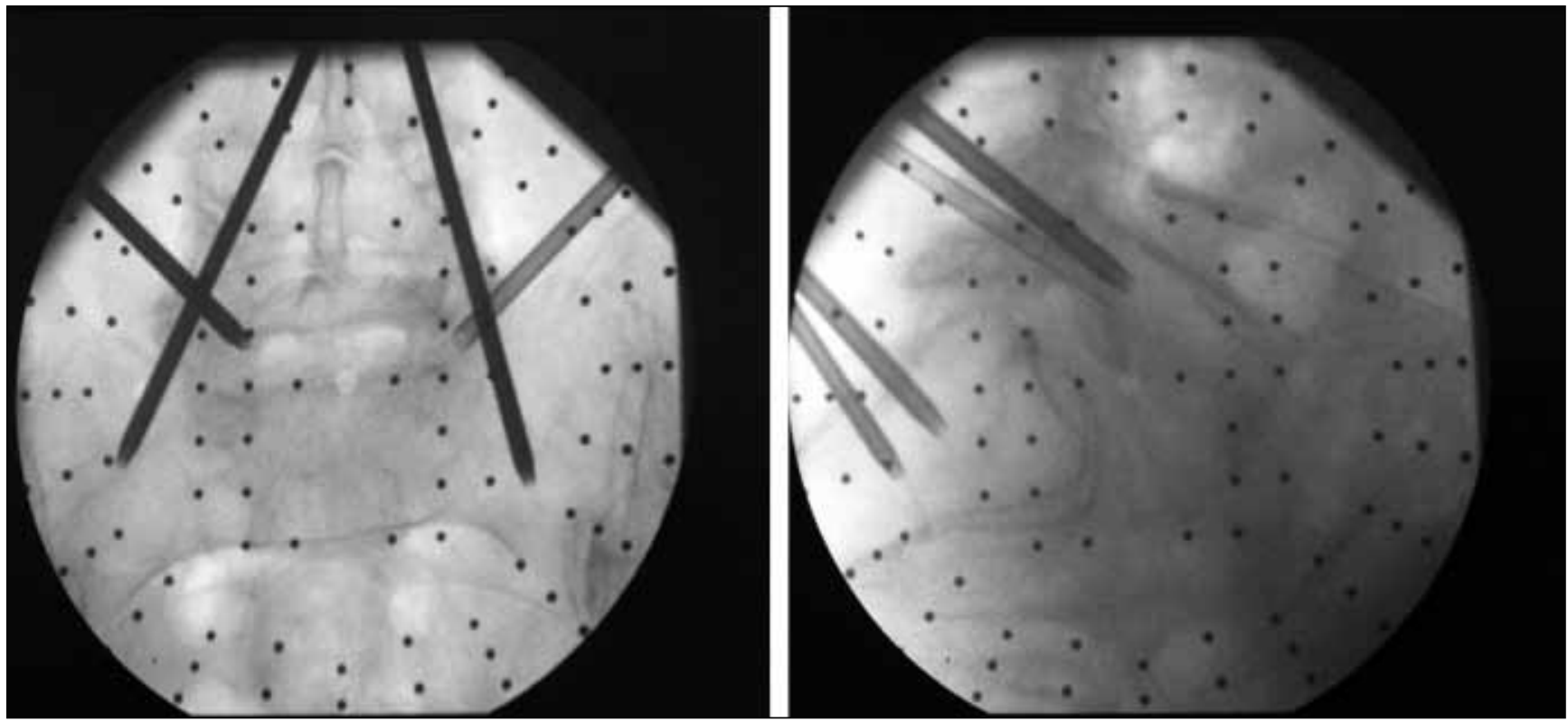

Figure 5: Intraoperative fluoroscopic images of lumbosacral spine showing position of cannulas within L5 vertebra body and sacral wings in AP and lateral images.

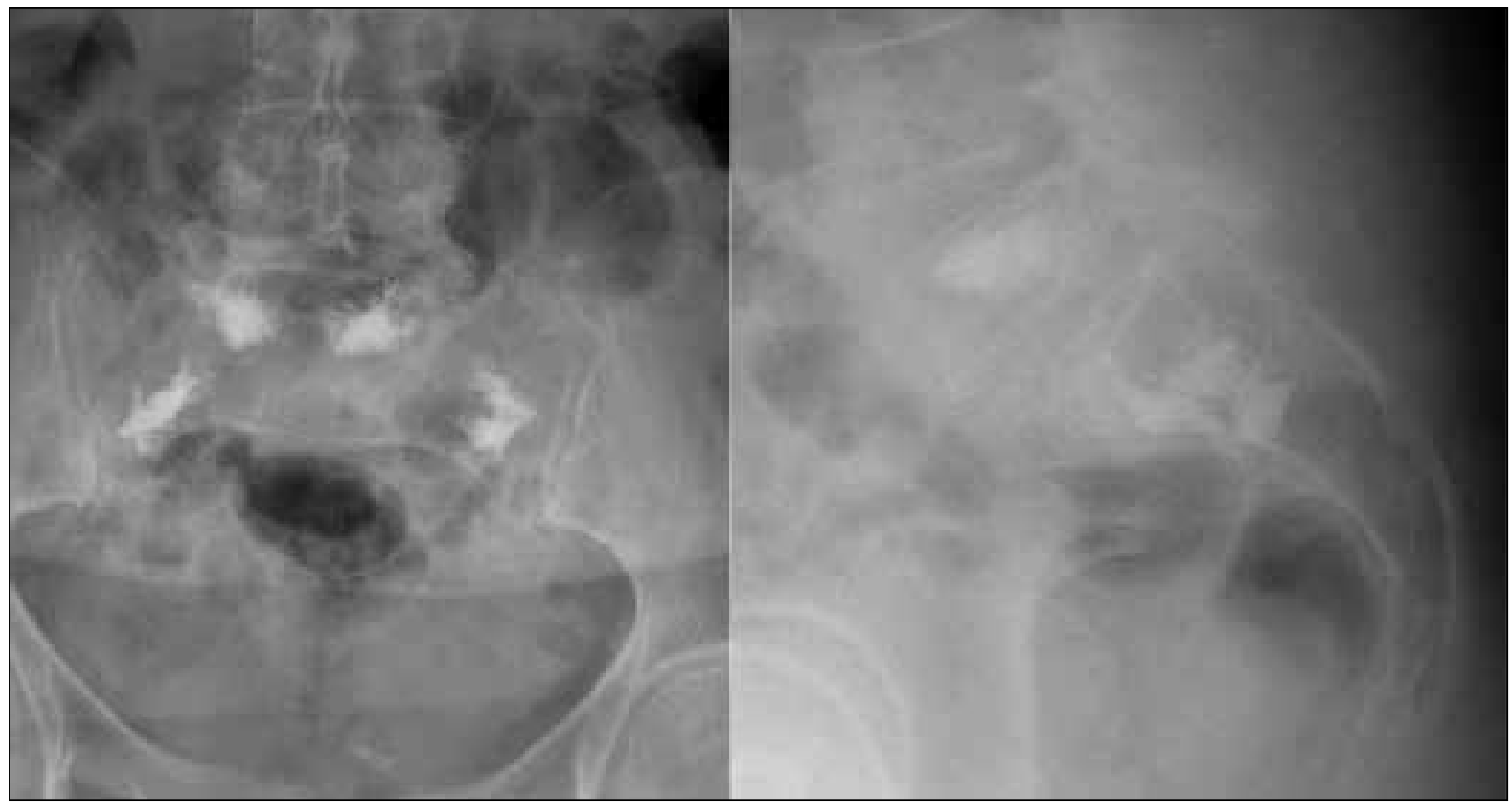

Figure 6: Postoperative AP and lateral lumbosacral spine radiographs showing PMMA within vertebral body and sacral wings. 
that this radiation for the surgeons was reduced by $50-70 \%$ when using the robot (2).

As mentioned, both methods involve significant radiation exposure. The highest rate of fluoroscopic imaging is required when sacroplasty is planned and the procedure has advanced to the drilling stage. At this point, the use of robotic guidance ensures safe placement of the cannula into the target point, based on the preoperative planning. At this stage, AP and oblique images are required to match fluoroscopic images gained by C-arm fluoroscopy with tomographic images saved to the system. These two images are enough for optimum K-wire and cannula placement. AP fluoroscopic images should be later obtained two or three times to avoid PMMA leakage when cement is injected.

The surgical planning and preparation stage takes 15 minutes. However, this loss can be ignored because the procedure is more reliable and there is less radiation exposure.

\section{CONCLUSION}

Sacroplasty is an effective method for treating SIFs. However, technical challenges encountered during its application are significant drawbacks of sacroplasty under CT and C-arm fluoroscopy. This study confirms that robotic-guided sacroplasty not only offers a safe and accurate cannula placement but also decreases the amount of radiation exposure to the operating staff.

\section{REFERENCES}

1. Anderson DE, Cotton JR: Mechanical analysis of percutaneous sacroplasty using CT image based finite element model. Med Eng Phys 29: 316-325, 2007

2. Barzilay Y1, Schroeder JE, Hiller N, Singer G, Hasharoni A, Safran O, Liebergall M, Itshayek E, Kaplan L: Robot-assisted vertebral body augmentation: A radiation reduction tool. Spine (Phila Pa 1976) 39(2):153-157, 2014

3. Bayley E, Srinivas S, Boszczyk BM: Clinical outcomes of sacroplasty in sacral insufficiency fractures: A review of the literature. Eur Spine J 18:1266-1271, 2009

4. Binaghi S, Guntern D, Schnyder P, Theumann N: A new, easy, fast, and safe method for CT-guided sacroplasty. Eur Radiol 16: 2875-2878, 2006

5. Boszczyk BM, Bierschneider M, Panzer S, Panzer W, Harstall R, Schmid K, Jaksche H: Fluoroscopic radiation exposure of the kyphoplasty patient. Eur Spine J 15:347-355, 2006

6. Brook AL, Mirsky DM, Bello JA: Computerized tomography guided sacroplasty: A practical treatment for sacral insufficiency fracture. Case report. Spine (Phila Pa 1976) 30: 450-454, 2005

7. Buerger PM, Peoples JB, Lemmon GW, McCarthy MC: Risk of pulmonary emboli in patients with pelvic fractures. Am Surg 59: 505-512, 1993

8. Dalbayrak S, Onen MR, Yılmaz M, Naderi S: Clinical and radiographic results of balloon kyphoplasty for treatment of vertebral body metastases and multiple myelomas. Journal of Clinical Neuroscience 17: 219-224, 2010

9. Fransen P: Fluoroscopic exposure in modern spinal surgery. Acta Orthop Belg 77:386-389, 2011
10. Geerts WH, Code KI, Jay RM: A prospective study of venous thromboembolism after major trauma. N Engl J Med 331: 1601-1606, 1994

11. Gjertsen O, Schellhorn T, Nakstad PH. Fluoroscopy-guided sacroplasty: Special focus on preoperative planning from three-dimensional computed tomography. Acta Radiol 49:1042-1048, 2008

12. Gotis Graham I, McGuigam L, Diamond T, Portek I, Quinn R, Sturgess A, Tulloch R: Sacral insufficiency fractures in the elderly. J Bone Joint Surg Br 76(6): 882-886, 1994

13. Grant M: Sacroplasty: A new treatment for sacral insufficiency fracture. J Vasc Interv Radiol 13:1265-1274, 2002

14. Grasland A, Pouchot J, Mathieu A, Paycha F, Vinceneux P: Sacral insufficiency fractures, an easily overlooked cause of back pain in elderly women. Arch Intern Med 156: 668-674, 1996

15. Harper CM, Lyles YM: Physiology and complications of bed rest. J Am Geriatr Soc 36:1047-1054, 1988

16. Kang SE, Lee JW, Kim JH, Park KW, Yeom JS, Kang HS: Percutaneous sacroplasty with the use of C-arm flat-panel detector CT: Technical feasibility and clinical outcome. Skeletal Radiol 40:453-460, 2011

17. Kang SS, Kim HC, Park JH, Hong SJ, Kim IS, Shin KM: Three- dimensional C-arm computed tomography-guided sacroplasty for the treatment of sacral body fracture. Spine (Phila $\mathrm{Pa}$ 1976) 34: 309-311, 2009

18. Kantelhardt SR, Martinez R, Baerwinkel S, Burger R, Giese A, Rohde V: Perioperative course and accuracy of screw positioning in conventional, open robotic-guided and percutaneous robotic-guided, pedicle screw placement. Eur Spine J 20:860-868, 2011

19. Layton KF, Thielen KR, Wald JT: Percutaneous sacroplasty using CT fluoroscopy. Am J Neuroradiol 27:356-358, 2006

20. Lee J, Stayman JW, Otake Y, Schafer S, Zbijewski W, Khanna AJ, Prince JL, Siewerdsen JH: Volume of change cone beam CT for image guided surgery. Phys Med Biol 7: 4969-4989, 2012

21. Naderi S, Ilaslan H, Aslan A, Koc ON, Dalkilic T: Sacroplasty: Report of three case. Turk Neurosurg 20:418-422, 2010

22. Onen MR, Yilmaz M: Kyphoplasty in the treatment of painful osteoporotic vertebral compression fractures. Journal of Turkish Spinal Surgery 23:307-318, 2012

23. Shoman M, Lieberman IH, Benzel EC, Togawa D, Zehavi E, Zilberstein B, Roffman M, Bruskin A, Fridlander A, Joskowicz $\mathrm{L}$, Brinkdanan S, Knoller N: Robotic assisted spinal surgery from concept to clinical practice. Computer Aided Surgery 12:105-115, 2007

24. Smith DK, Dix JE: Percutaneous sacroplasty: Long axis injection technique. Am J Roentgenol 186:1252-1255, 2006

25. Sun G, Jin P, Li M, Liu XW, Li FD: Three-dimensional C-arm computed tomography reformation combined with fluoroscopic-guided sacroplasty for sacral metastases. Support Care Cancer 20:2083-2088, 2012

26. Waites MD, Mears SC, Richards AM, Mathis JM, Belkoff SM: A biomechanical comparison of lateral and posterior approaches to sacroplasty. Spine (Phila Pa 1976) 33:735-738, 2008

27. Weber M, Hasler P, Gerber H: Insufficiency fractures of the sacrum: Twenty cases and review of the literature. Spine (Phila Pa 1976) 16:2507-2521, 1993 